\title{
Training Hazardous-Materials Response Teams and Chemistry Students through Practical Experimentation
}

\author{
Ernst Hungerbühler ${ }^{*}$ and Markus Gisler
}

\begin{abstract}
Large quantities of hazardous substances are required to meet the needs of today's industrial society. During the manufacture, transport, and use of these substances - whether they serve as raw materials, intermediate products or energy carriers - accidents and damage cannot be totally excluded despite all the efforts and technical knowledge that may go into their prevention. Incidents involving hazardous chemicals always represent a substantial risk for accident response teams, the general population, and the environment. In order to keep damage to a minimum, special attention must be given to training the specialists involved. It is possible to demonstrate the risks resulting from hazardous materials and the most suitable methods of effectively combating such risks by the use of thought-provoking practical experiments. This is shown with a number of examples.
\end{abstract}

Keywords: Characteristics of liquid and gas fires - Chemical hazards · Education and experimentation · Explosion and explosion prevention experiments · Training hazardous-materials response teams

\section{Introduction}

Identifying potential dangers resulting from accidents with chemicals (Fig. 1 and 2) or their incorrect handling and successfully combating these requires specialized knowledge.
Correspondence: Prof. Dr. E. Hungerbühler University of Applied Sciences Basel (FHBB)

Gründenstrasse 40

$\mathrm{CH}-4132$ Muttenz

Tel.: +41614674388

Fax: +41614674457

E-Mail: e.hungerbuehler@fhbb.ch

Dr. M. Gisler

Clariant (Switzerland) AG

TechCenter Reinach

Rothausstrasse 61

$\mathrm{CH}-4132$ Muttenz 1

Tel.: +41614697997

E-Mail: markus.gisler@clariant.com

§Alongside their activities as Head of the Chemistry Department at the University of Applied Sciences, Basel, and as Group Leader R\&D Dyestuffs at Clariant, respectively, the authors are also consultants in chemical matters to the Canton of Aargau and head and deputy-head, respectively, of the chemical and oil protection unit of the Rheinfelden fire service.
As the officers in charge of units first responding to a 'chemical incident' are not normally specialists but all-round fire fighters, they must be able to rapidly identify by means of checklists (Fig. 3 and 4 ) and simple pictures, such as the fire triangle below (Fig. 5), immediately comprehensible warning signs (Fig. 3), hazard labels (Fig. 4) or transport documents, - what particular dangers might result from the materials involved. This makes it possible for the correct measures to be taken to effectively combat the problem (Fig. 6) and to protect people, property, and the environment, without the fire-fighting team being exposed to unnecessary risks.

Nowadays, in the event of an emergency alarm, it is possible to call on chemicals specialists from hazardous-materials response teams in the chemical industry and on chemicals consultants to help in combating an incident. Only by means of on-going training (Fig. 7) and practical exercises involving cooperation between firefighting services, hazardous-materials response teams from the chemical industry, chemicals consults, civil defense units, and possibly those responsible in organizations at the local authority level is it possible for these various specialists to function as an effective team that can give valuable support to the person in charge of operations in an emergency.

\section{Teaching through Experimentation}

By means of specifically tailored training courses, the Chemistry Department of the University of Applied Sciences, Basel, increases the awareness and motivation of chemistry students and industrial safety officers to make an active contribution to chemical safety and environmental protection (Fig. 8 and 9).

In order to encourage an interest in people to become chemicals consultants or fire fighters with a chemistry background, the Chemistry Department of the University of Applied Sciences, Basel, has included a special module dealing with chemical safety in its Basic Chemistry course for firstyear students. One section of this module, which is being constantly expanded, provides practice-oriented visualization of chemical safety and environmental protection using interesting and thought-provoking experiments.

The aim of these experiments is to make our specialized audience more aware of the problems that can result from an accident involving hazardous materials and to give them confidence in their personal protective equipment, in the materials used to combat incidents and in the measuring devices at their disposal.

Since we have been making it possible for students to be actively involved in ex- 


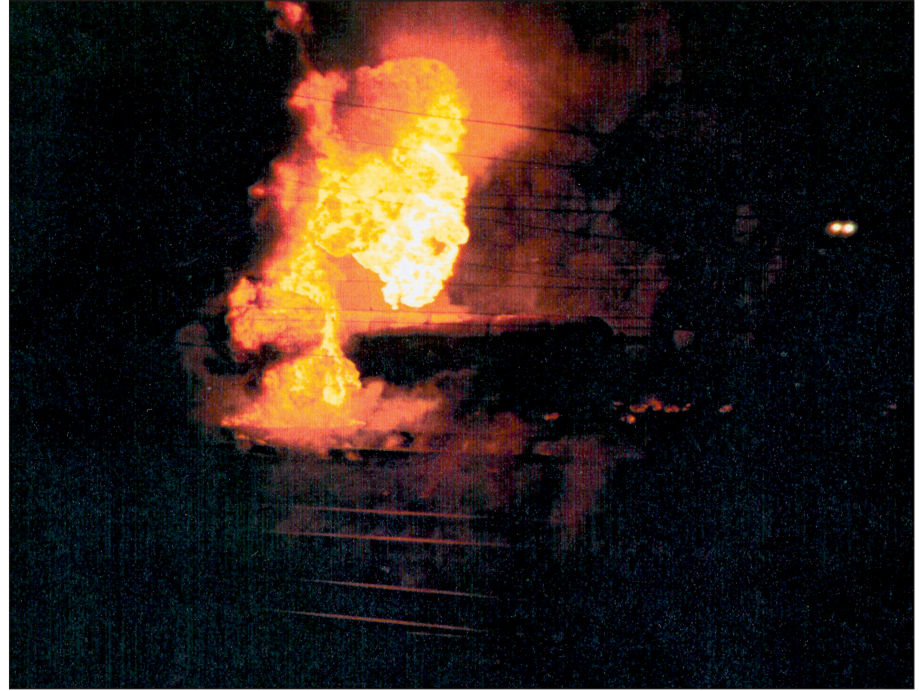

Fig. 1. Stein-Säckingen 1991, derailment of tank cars containing gasoline and resultant fire (Picture: Rheinfelden fire service)

\section{Hazard ID Number UN- Number}

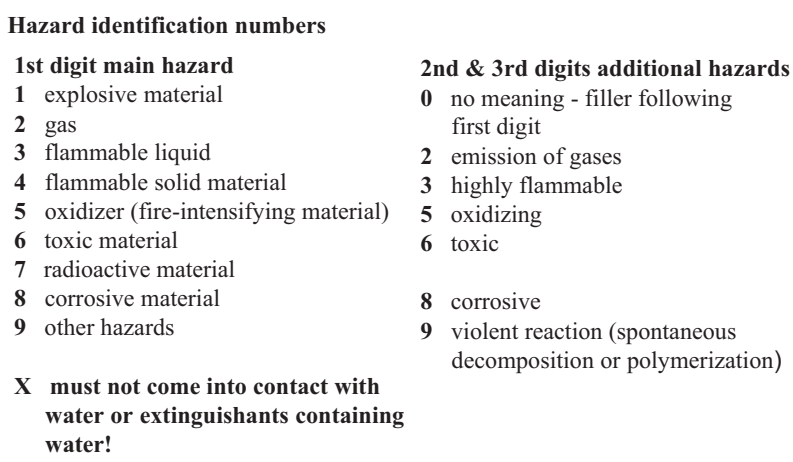

2nd \& 3rd digits additional hazards

no meaning - filler following

2 emission of gases

3 highly flammable

5 oxidizing

8 corrosive

violent reaction (spontaneous decomposition or polymerization)

Fig. 3. Hazard ID number 33: highly flammable liquid, Material number 1203: gasoline [1]

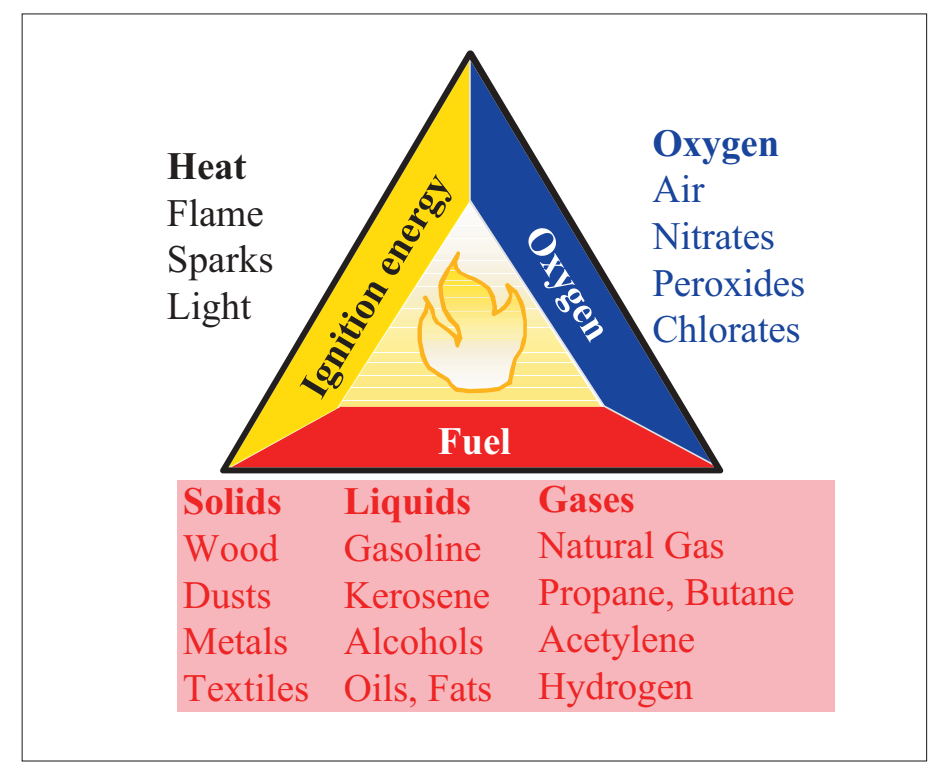

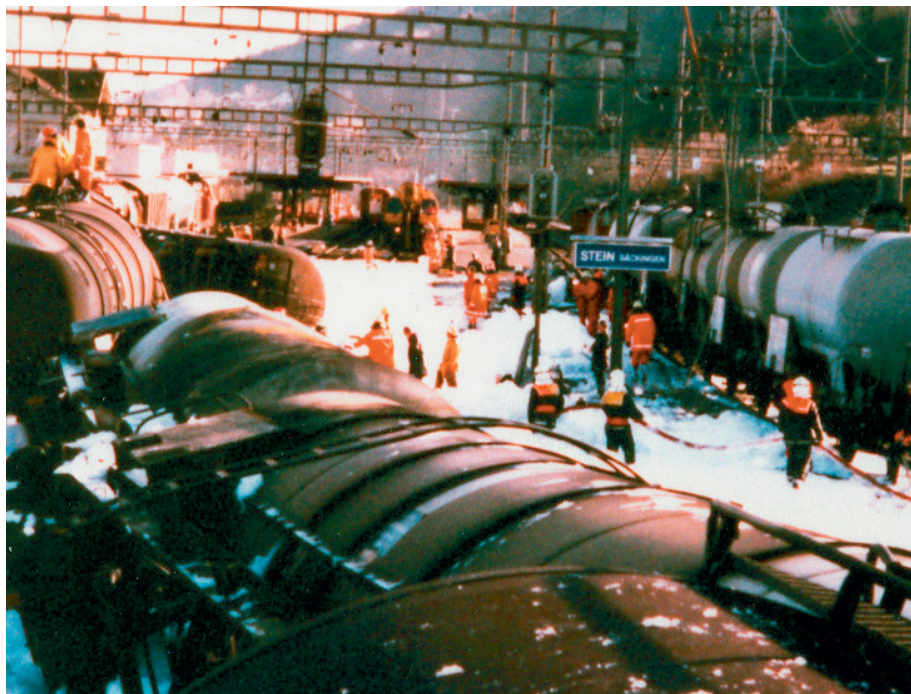

Fig. 2. Stein-Säckingen 1991, gasoline tank cars after extinction of fire and treatment with foam (Picture: Rheinfelden fire service)
Fig. 4. Hazard labels

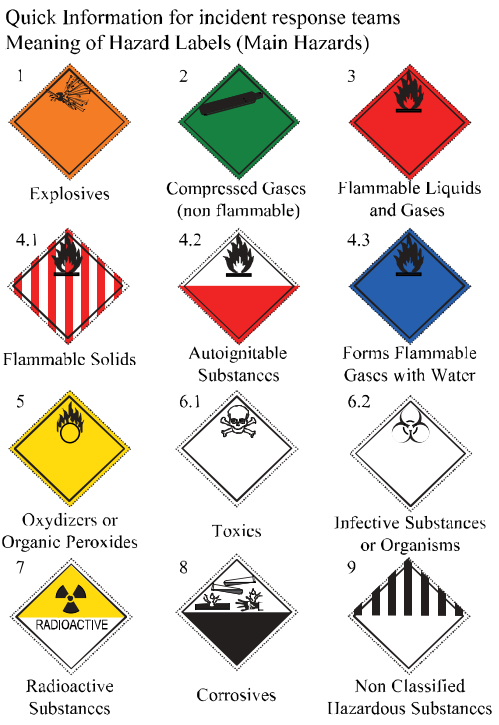




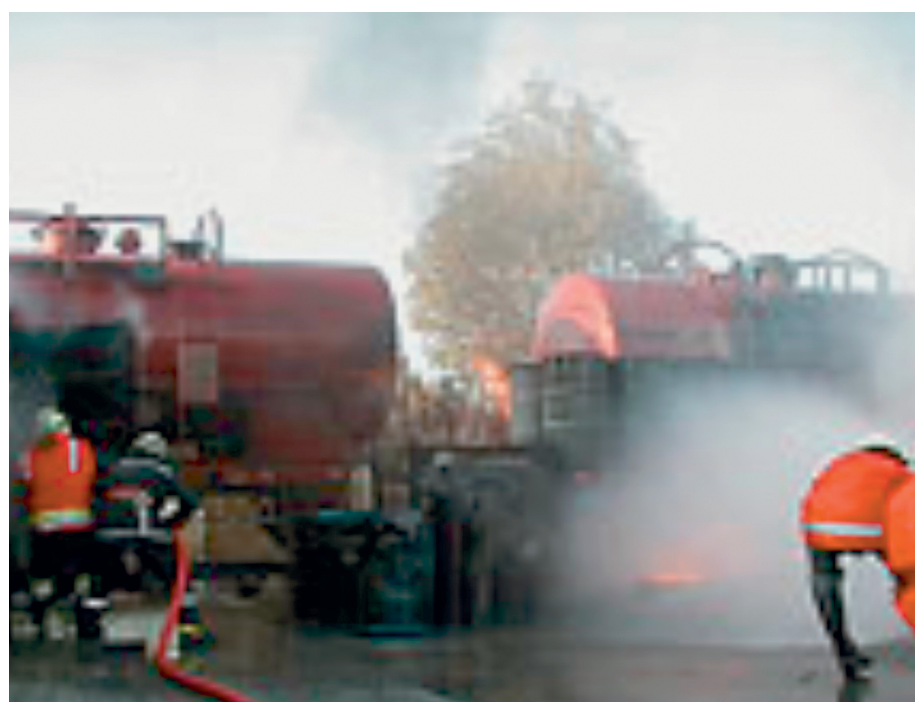

Fig. 7. Practice makes perfect; emergency drill at the Siegfried chemical accident training center [2]

Fig. 9. Students watching an experiment in class: ammonium bichromate $\mathrm{NH}_{4} \mathrm{Cr}_{2} \mathrm{O}_{7}$ burns (even without external oxygen) to form chrome-III-oxide $\mathrm{Cr}_{2} \mathrm{O}_{3}$ and nitrogen $\mathrm{N}_{2}$
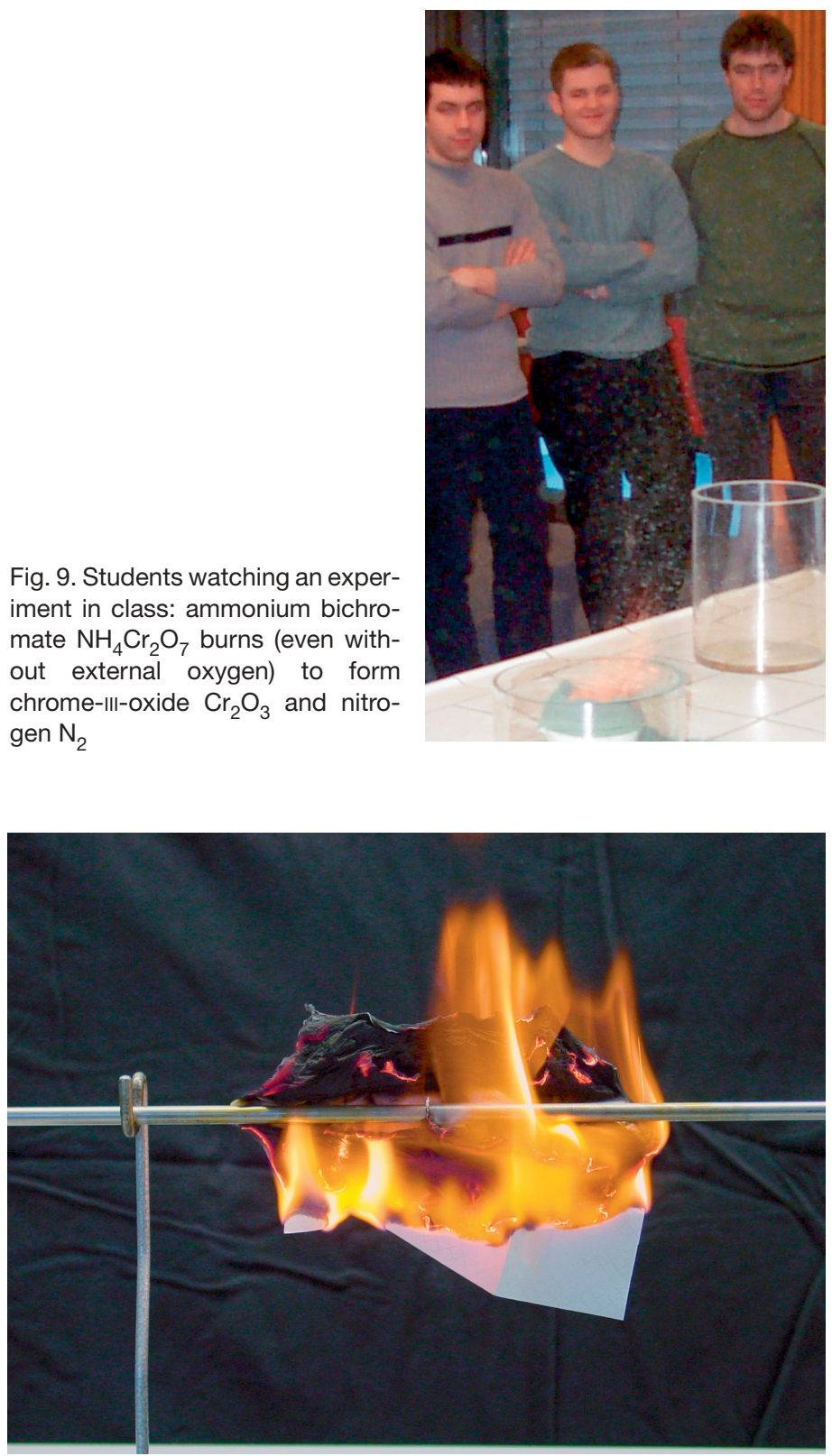

Fig. 11. Combustion of a paper handkerchief soaked in pure alcohol results in complete destruction

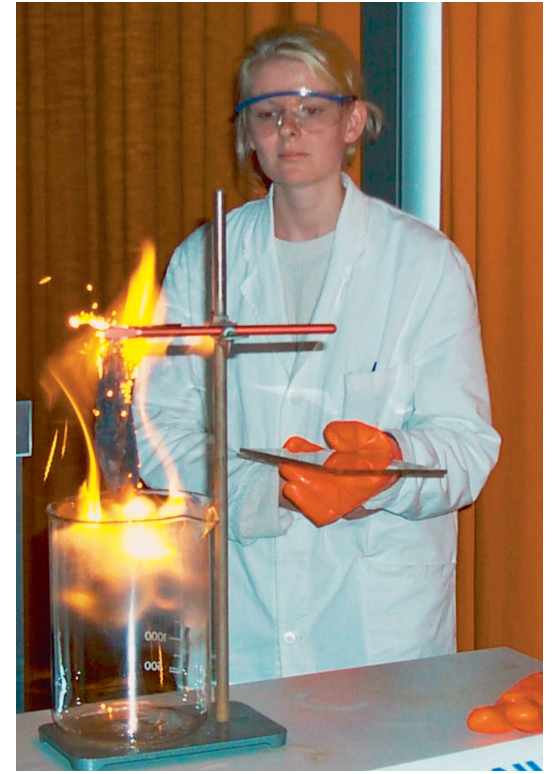

Fig. 8. Trainee Susanne Mau performing an experiment: steel wool and a 4.5-volt flashlight battery are used to set fire to ether in a beaker

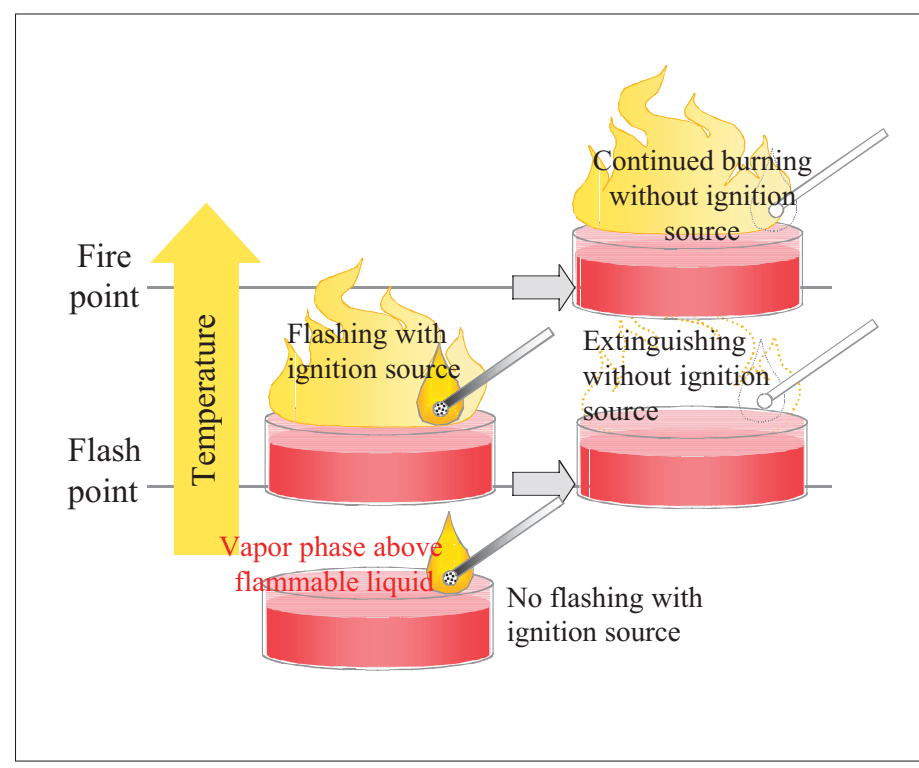

Fig. 10. Flash point and fire point

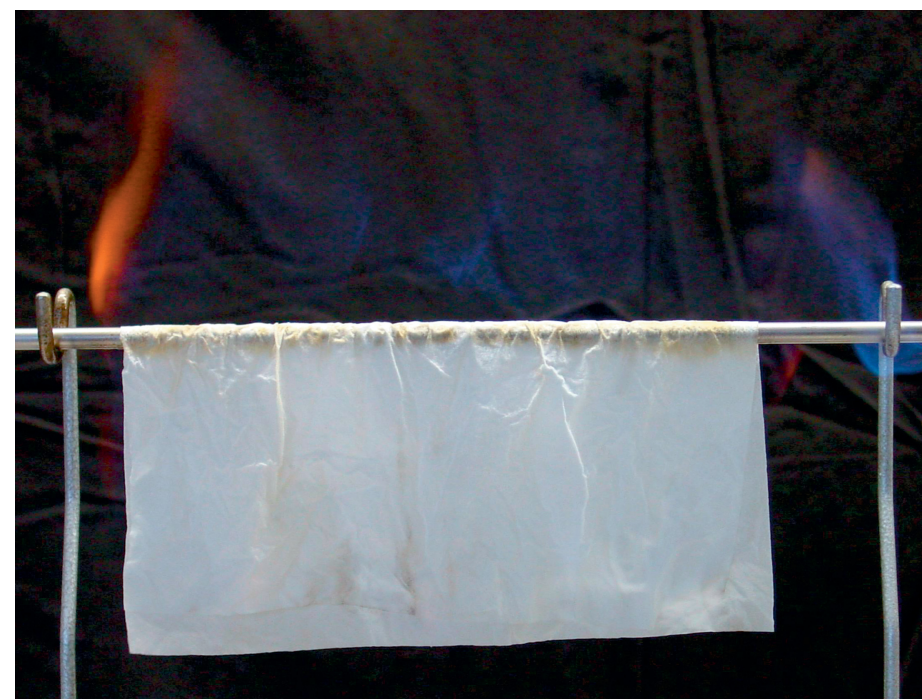

Fig. 12. A paper handkerchief soaked in $50 \%$ water-alcohol solution remains intact both during and after combustion 


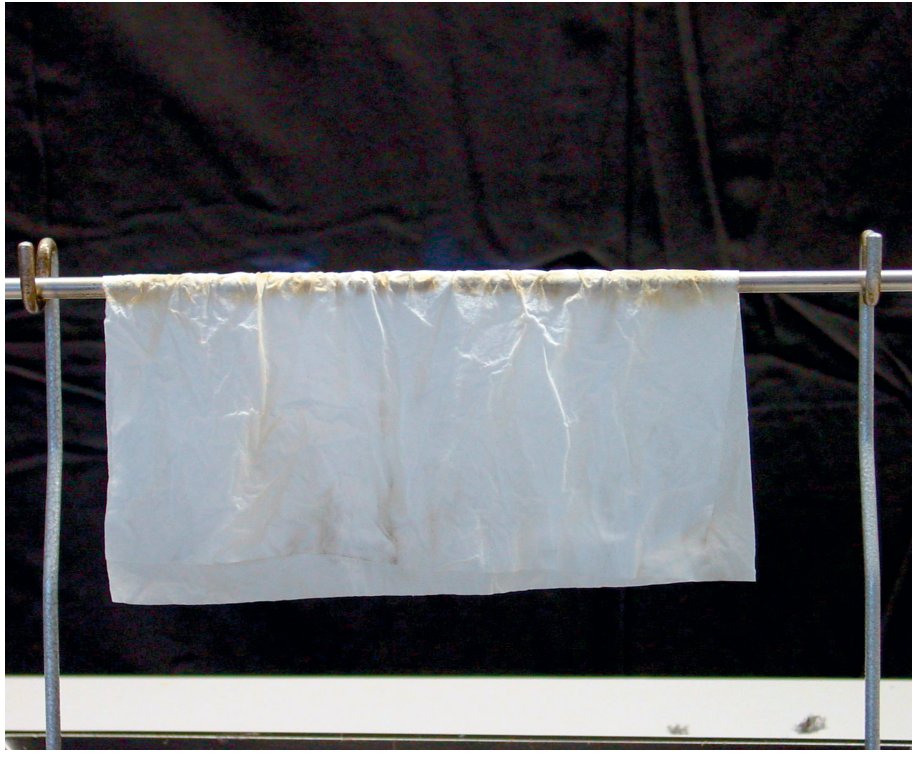

Fig. 13. A paper handkerchief soaked in $50 \%$ water-alcohol solution remains intact after combustion

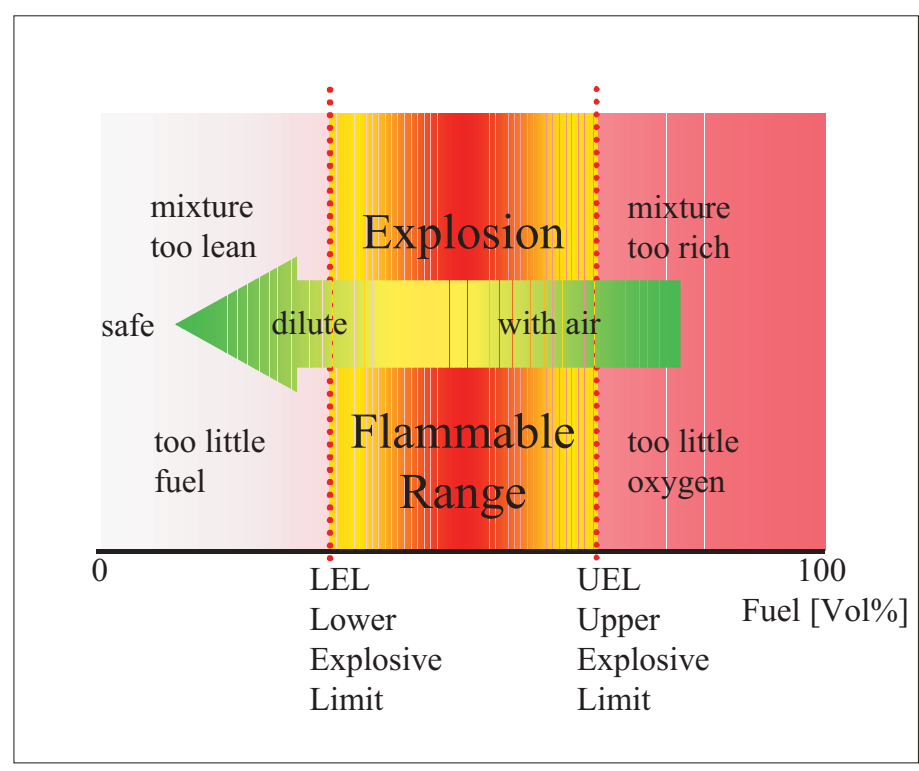

Fig 14. Explosive range and explosive limits periments, we have observed an impressive increase in the attention they pay to the subject of chemical safety and their greater pleasure in professional experimentation. Recently students who have become used to this form of experimentation have also had the opportunity to demonstrate the know-how they have acquired to school pupils interested in science, to both former and potential chemistry students and to visitors and thus to give them an insight into how training in chemical safety and the work environment can be bolstered by means of practical experimentation.

\section{Flammable Liquids}

Hazard ID numbers:

30: flammable liquid (flash point between $21^{\circ} \mathrm{C}$ and $100^{\circ} \mathrm{C}$ )

33: highly flammable liquid (flash point below $21^{\circ} \mathrm{C}$ )

The flash point of a liquid is a materialspecific value indicating the temperature at which the substance in question catches fire upon contact with a source of ignition under standardized experimental conditions (Fig. 10). For gasoline, the literature gives $-20{ }^{\circ} \mathrm{C}$ [1], and for fuel oil or diesel fuel $>55^{\circ} \mathrm{C}[1]$. Accordingly, fuel oil cannot be set alight at room temperature through contact with an ignition source - quite unlike gasoline! Only when the fuel oil has been heated to $60-70{ }^{\circ} \mathrm{C}$ can it also be set on fire.

By increasing the surface area of a material, e.g. by vaporization or adsorption in a porous carrier such as an oil binding agent, it becomes possible for substances, such as diesel oil that would not otherwise catch fire to be set alight at room temperature.

The boiling point and vapor pressure of a liquid, also material-specific values, tell us something about the evaporation properties of the substance and its propensity to form an explosive hazardous material/mixture with air. Hazardous mixtures of this kind can be identified with an explosimeter and evaluated.

Flammable organic liquids can also be evaluated on the basis of their miscibility with water: hydrophilic liquids are miscible with water. In the event of fire, such mixtures can be effectively extinguished by means of cooling and diluting with water or by being covered with a carpet of foam. The good cooling effect of water (high specific evaporation temperature) can be demonstrated easily by means of the experiment (Fig. 11 to 13)

Hydrophobic liquids mix poorly with water or not at all. In addition, if they also have a lower specific gravity than water, e.g. gasoline, these liquids float on the surface of the water and cannot be extinguished simply with water in the event of fire. Foam acts as an ideal extinguisher by completely cutting the burning material off from the oxygen contained in the air, which leads to the fire being smothered. Alternatively, a fire of this type can be extinguished using $\mathrm{CO}_{2}$ or powder, although in this case the powder residue that settles everywhere can make large-scale additional cleaning necessary.

\section{Explosive Vapor-Air Mixtures}

Wüthrich defines an explosion as the sum of the phenomena that occur in the event of the rapid release of energy [3]. $\mathrm{He}$ specifies a chemical explosion by the energy release of forces between valence electrons as opposed, for instance, to a nuclear explosion with reactions occurring inside the nucleus [3].
We use the term 'explosion' here as a synonym for chemical explosion.

The minimum concentration of a flammable substance in the air ( $\mathrm{vol} / \mathrm{vol} \%)$ at which the mixture can still explode is referred to as its lower explosive limit (LEL) (Fig. 14). With the aid of an explosimeter (for function, see Fig. 15), it is possible to detect a potentially hazardous situation considerably below the LEL and to take suitable measures.

\section{Explosions of Detonating Gases (Hydrogen/Oxygen or Hydrogen/ Atmospheric Oxygen Mixtures)}

\section{Experiment 1: Exploding Balloons}

Three balloons are filled with pure oxygen, pure hydrogen (diameter less than 30 $\mathrm{cm}$ ), and a mixture of approx. two parts by volume hydrogen and one part by volume oxygen (diameter less than $20 \mathrm{~cm}$ ), respectively. Using a candle on a stick, the balloon containing the oxygen is first ignited and noted as a blank value, since oxygen itself is known not to burn. Then follows the balloon with pure hydrogen, which explodes with a muffed bang and creates a clearly visible fireball. The balloon filled with the detonating gas mixture should only be exploded when those present have protected their ears and opened their mouths slightly since it explodes with a violent, very loud bang.

\section{Experiment 2: Exploding Can}

An empty one-liter can with the lid removed has a hole approx. $2 \mathrm{~cm}$ in diameter made in the bottom, which is closed with a bung. The can is placed on a smooth surface with the opening facing downward and hydrogen gas is then slowly introduced into it 
Gas Mixture to be Measured

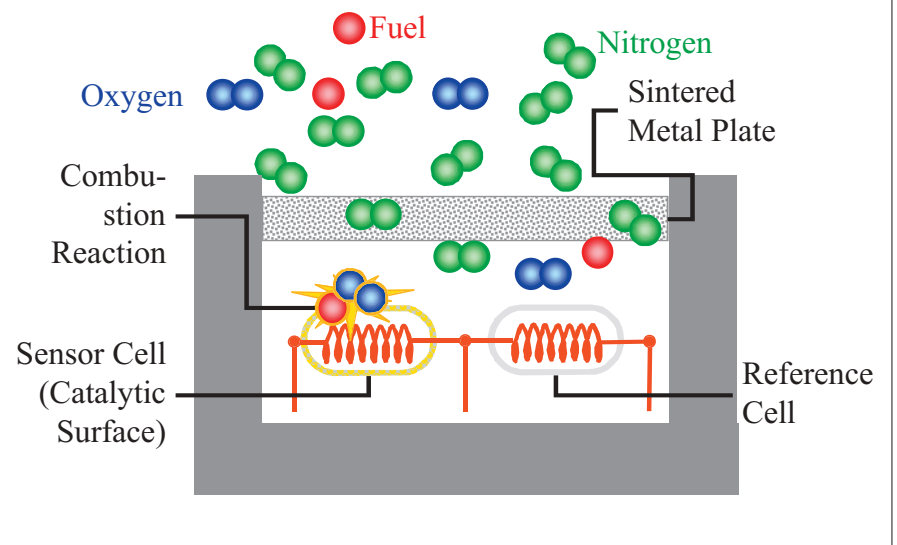

Fig. 15. How the sensor cell of an explosimeter works: The vaporous combustible material is burnt on the catalytically active surface of the sensor cell. The meter measures the difference in temperature between the sensor cell and a reference cell

Fig. 17. Hosepipe model to show how combustible vapors with a high specific gravity can spread. Acetone vapors created in the collecting vessel above (impregnated cotton-wool swab) spread through the coiled hosepipe, ignite on contact with the ignition source at the end (candle), then flare back and set fire to the supply of acetone

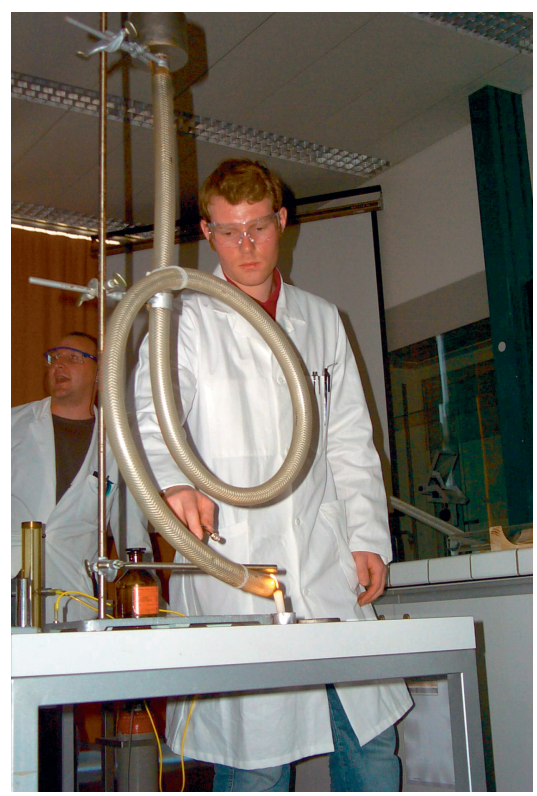

Deflagration: Flame passes through

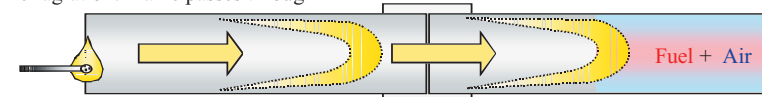

Foam Pad $\rightarrow$ Flame stops
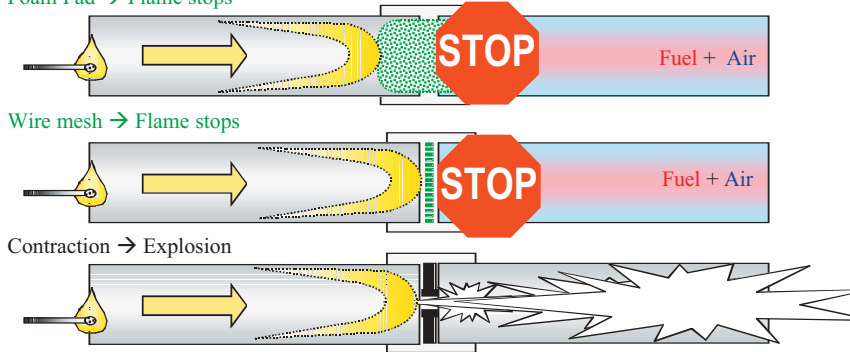

Fig. 19. Sewer experiments, effects of obstructions, schematic representation

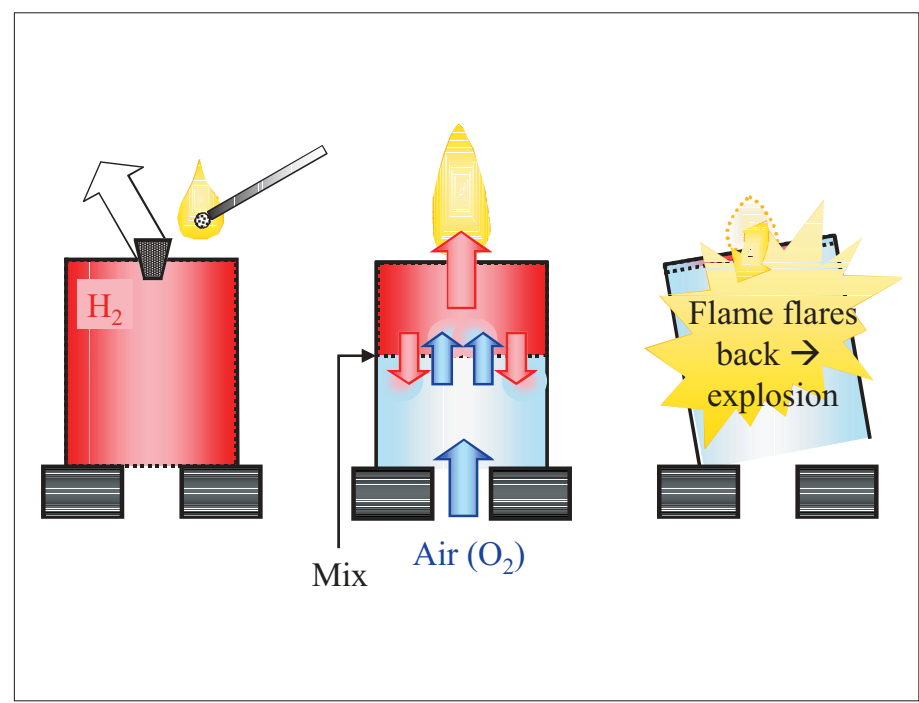

Fig. 16. Can with hydrogen

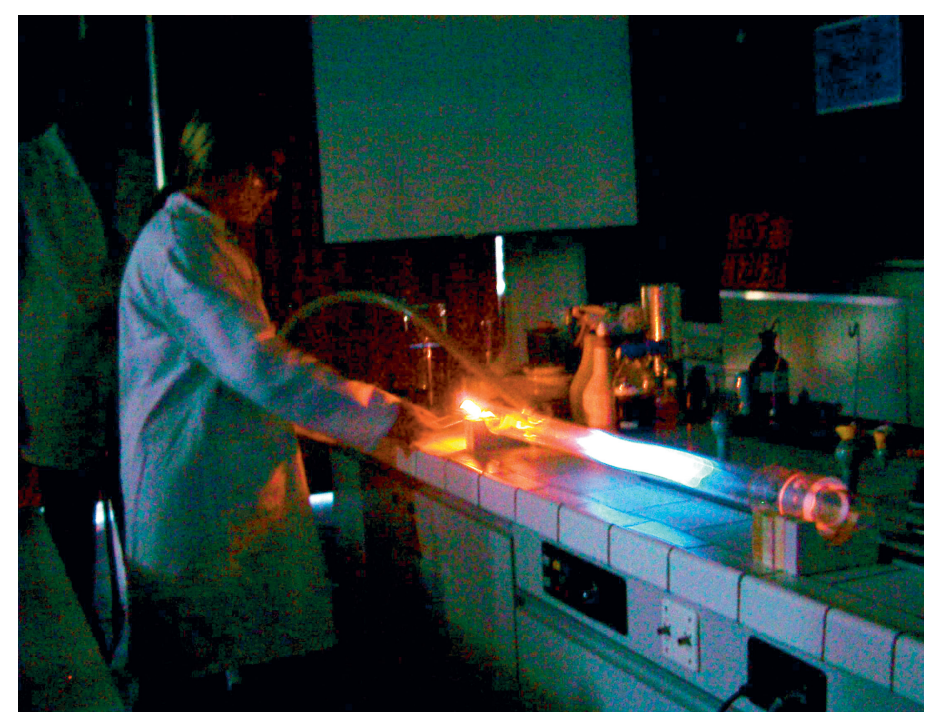

Fig. 18. Simulation of sewer, course of fire in a four-meter-long acrylic glass tube filled with a mixture of propane gas and air

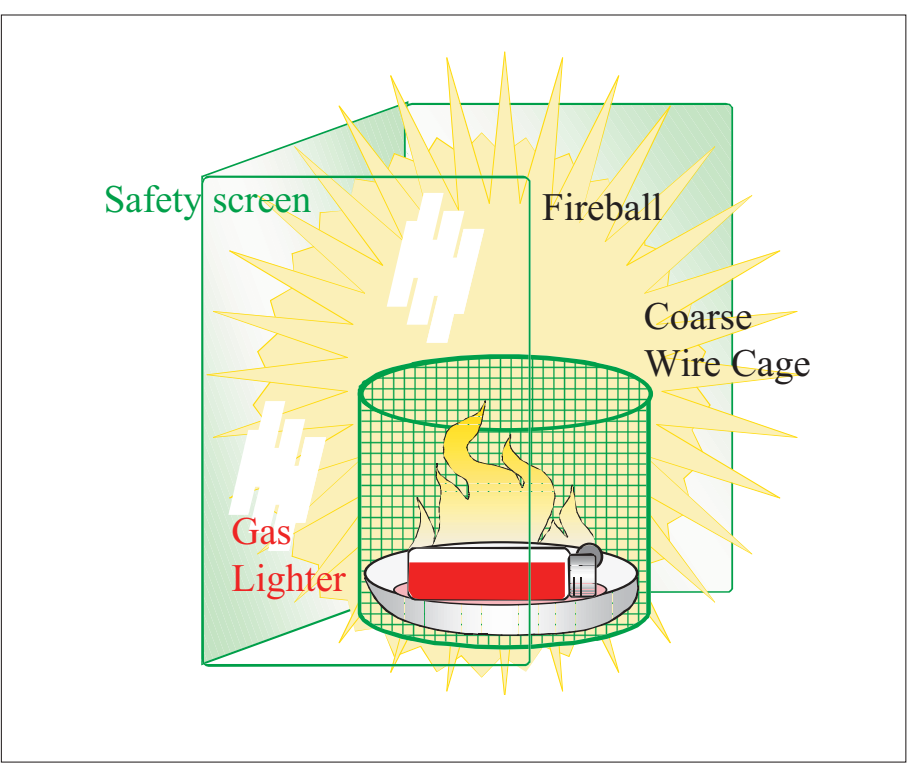

Fig. 20. Bleve of a gas lighter, schematic diagram 
to force out the atmospheric oxygen until the can is full of sufficient $\mathrm{H}_{2}$ for the upper explosive limit of $74 \%$ [1] to have been substantially exceeded. The can acts like a diving bell and retains the hydrogen with its lower specific gravity (Fig. 16).

When the bung is removed and the escaping gas ignited, air penetrates into the can from the lower open end and mixes with the hydrogen. The flame continues to burn for a while, but becomes increasingly smaller until the flame flares back into the container and a violent explosion occurs with a loud bang.

\section{Measures}

A comprehensive overview of explosion prevention has been published by Bartknecht [4]. Roessler provides a detailed description of the safety aspects of catalytic hydrogenation [5].

Inerting, e.g . by means of nitrogen, $\mathrm{CO}_{2}$ or argon, can frequently prevent an explosive gas atmosphere by excluding oxygen. Relieving pressure, accurate knowledge of reactions including risk analysis and staff training are additional important measures to ensure that processes involving hydrogen can be implemented safely.

Obermüller has recently described an explosion prevention concept for a reaction in an oxygen atmosphere on a production scale [6].

\section{Experiment to Visualize the Hazards of Flammable Vapors in a Sewer or Ventilation System}

This situation can never be excluded in the event of an accident involving flammable liquids or gases on the road, in a building or in a laboratory, which makes it essential for measures to be taken in order to keep an incident of this kind within limits (Fig. 17).

\section{Sewer Experiments}

Various constructional measures, such as fire-walls, fire-doors, and fire-prevention covers, can contain the spread of fire for a certain period of time and thus frequently prevent greater damage. Flammable vapors in a sewer represent a very great hazard to people and infrastructure should the lower explosive limit be exceeded. As there is generally no possibility of inerting measures being taken, it is only possible to prevent damage by means of venting or creating compartments or to limit damage in the event of ignition.

In practice, fire-fighters can create foam barriers in a sewer filled with flammable vapors by pumping extinguishing foam into the sewer.
The hazards and behavior of flammable vapors and gases in sewers can easily be demonstrated by a set of two acrylic glass tubes which are filled with a propane/air mixture. As shown in the experiments illustrated (Fig. 18 and 19), these can successfully contain an explosion in one section of the sewer.

When the connection between the two tubes is not obstructed, after ignition at one end, the flame front passes through the two tubes.

A pad of fire-fighting foam or a wire mesh screen inserted between the two tubes separates the tubes into two fire compartments and will prevent the flame from spreading. In these cases, the remaining gas/air mixture in the second tube can be ignited from the opposite end.

A ring-shaped contraction between the two tubes leads to an explosion in the second tube.

\section{Bleve of a Gas Lighter}

BLEVE is an acronym for Boiling Liquid Expanding Vapor Explosion.

Bleves are among the most dangerous incidents with which fire-fighting teams are confronted. Bleves occur when containers of liquids or liquid gases are heated or directly exposed to a fire. Without external cooling, the contents of the tank are heated, the pressure inside increases, and the temperature of the combustible contents soon passes boiling point. The section of the container skin that is exposed to the fire over the vapor phase heats up faster than the section filled with the combustible liquid and suffers a faster loss of stability.

The increasing internal pressure, coupled with the diminishing stability of the skin of the container can cause the container to burst. The contents that have been under pressure empty virtually instantaneously. The rapidly expanding vapor cloud burns in a huge fireball.

Only by means of massive cooling with water is it possible to keep a container of combustible material intact when it is located inside a fire, such as an 80,000-liter tank car of gasoline (Fig. 1).

\section{Experiment}

A small-scale bleve can be demonstrated by means of a disposable gas lighter (Fig. 20).

An evaporating dish containing a few milliliters of ethanol is placed behind a protective screen and a gas lighter put inside it. The alcohol is then set alight. A wire-mesh cage placed around the dish prevents any metal fragments from being scattered. After just a few minutes, the gas tank of the lighter bursts and the burning vapor cloud creates a fireball approximately $50 \mathrm{~cm}$ in diameter.

\section{Important}

This publication has been compiled to the best of the authors' knowledge and belief and is intended solely for specialists. Anyone using the information it contains, particularly with regard to performing experiments, does so at his/her own risk and on his/her own responsibility. All the experiments described here are potentially dangerous and should under no circumstances be attempted by laypersons. Unjustifiable risks involving potential harm to persons or property may occur if experiments are not correctly performed or if alterations are made to experimental parameters (quantities, etc.). The authors accept no liability for any direct or indirect damage that might result from the experiments described being carried out. In case of accident, it is always advisable to keep sensible extinguishing materials at hand (extinguishing blankets, $\mathrm{CO}_{2}$ ) together with a bucket of water that can be used for cooling purposes in the event of fire. Ensure that you switch off any exposed fire alarms before performing the experiments.

Never carry out an experiment in front of an audience for the first time; but only perform experiments that you have already documented well in advance and in a way that you have already found to be safe and successful. Check even the most insignificant alterations to previous experiments in advance by means of appropriate testing!

\section{Acknowledgements}

We would like to thank Hildolf Schwald for providing us with some of the experiments and for his technical assistance. We also thank Walter Hohl, Andre Büttler and our first-year chemistry students $(2002 / 2003)$ for their help in expanding our collection of experiments. And finally thanks to Robert Bannister, one of our professors of English at the FHBB, for translation.

Received: January 5, 2004

[1] G. Hommel, 'Hommel interaktiv, Handbuch der gefährlichen Güter', SpringerVerlag, Berlin, Heidelberg, 2003.

[2] Chemiewehrschule Siegfried AG, CH4800 Zofingen, www.chemiewehrschule.ch

[3] K. Wüthrich, Chimia 2003, 57, 757.

[4] W. Bartknecht, 'Explosionsschutz und Anwendungen', Springer-Verlag, Berlin, Heidelberg, 1993.

[5] F. Roessler, Chimia 2003, 57, 791.

[6] I. Obermüller, Chimia 2003, 57,784. 